\title{
Histone deacetylase-2: A potential regulator and therapeutic target in liver disease (Review)
}

\author{
YA-RU LIU ${ }^{1-3 *}$, JIE-QUAN WANG ${ }^{4,5^{*}}$, ZHAO-GANG HUANG $^{1,2}$, RUO-NAN CHEN $^{1,2}$, XI CAO $^{1,2}$, \\ DONG-CHUN ZHU ${ }^{1,2}$, HAI-XIA YU ${ }^{1,2}$, XIU-RONG WANG ${ }^{1,2}$, HAI-YUN ZHOU ${ }^{1,2}$, QUAN XIA ${ }^{1,2}$ and JUN LI $^{3}$ \\ ${ }^{1}$ Department of Pharmacy, The First Affiliated Hospital of Anhui Medical University; ${ }^{2}$ Department of Pharmacy, \\ The Grade 3 Pharmaceutical Chemistry Laboratory of State Administration of Traditional Chinese Medicine, \\ Hefei, Anhui 230022; ${ }^{3}$ The Key Laboratory of Anti-inflammatory Immune Medicines, School of Pharmacy, \\ Anhui Medical University, Ministry of Education, Hefei, Anhui 230032; ${ }^{4}$ Department of Pharmacy, \\ Affiliated Psychological Hospital of Anhui Medical University; ${ }^{5}$ Department of Pharmacy, \\ Hefei Fourth People's Hospital, Hefei, Anhui 230000, P.R. China
}

Received July 28, 2020; Accepted April 12, 2021

DOI: 10.3892/ijmm.2021.4964

\begin{abstract}
Histone acetyltransferases are responsible for histone acetylation, while histone deacetylases (HDACs) counteract histone acetylation. An unbalanced dynamic between histone acetylation and deacetylation may lead to aberrant chromatin landscape and chromosomal function. HDAC2, a member of class I HDAC family, serves a crucial role in the modulation of cell signaling,immune response and gene expression. HDAC2 has emerged as a promising therapeutic target for liver disease by regulating gene transcription, chromatin remodeling, signal transduction and nuclear reprogramming, thus receiving attention from researchers and clinicians. The present review introduces biological information of HDAC2 and its physiological and biochemical functions. Secondly, the functional roles of HDAC2 in liver disease are discussed in terms of hepatocyte apoptosis and proliferation, liver regeneration, hepatocellular carcinoma, liver fibrosis and non-alcoholic steatohepatitis. Moreover, abnormal expression of HDAC2 may be involved in the pathogenesis of liver disease, and its expression levels and pharmacological activity may represent potential biomarkers of liver disease. Finally, research on
\end{abstract}

Correspondence to: Professor Quan Xia, Department of Pharmacy, The First Affiliated Hospital of Anhui Medical University, 218 Jixi Road, Hefei, Anhui 230022, P.R. China

E-mail: xiaquan2010@163.com

Professor Jun Li, The Key Laboratory of Anti-inflammatory Immune Medicines, School of Pharmacy, Anhui Medical University, Ministry of Education, 81 Meishan Road, Hefei, Anhui 230032, P.R. China

E-mail: lijunahmu@163.com

*Contributed equally

Key words: histone deacetylase 2, liver disease, inhibitor, non-coding RNA selective HDAC2 inhibitors and non-coding RNAs relevant to HDAC2 expression in liver disease is also reviewed. The aim of the present review was to improve understanding of the multifunctional role and potential regulatory mechanism of HDAC2 in liver disease.

\section{Contents}

1. Introduction

2. HDAC2

3. Role of HDAC2 in hepatocyte apoptosis and proliferation

4. HDAC2 in liver disease

5. Conclusion

\section{Introduction}

The level of histone acetylation is of importance for nuclear stability, chromatin structure, gene expression and physiological functions in hepatocytes $(1,2)$. Histone acetyltransferases (HATs) and histone deacetylases (HDACs) are antagonistic proteases that serve regulatory roles in the balance of histone acetylation and deacetylation in nucleosomes (3). HATs, which favor of histone acetylation, transfer acetyl groups from acetyl-CoA to the $\varepsilon-\mathrm{NH}_{2}$ group of lysine residue side chains and neutralize the positive charge of histone tails, thus making chromatin structure more loose and conducive to active transcription (4-6). HDACs, which facilitate histone deacetylation, remove the acetyl group from the $\varepsilon$-amino group of lysine residue side chains, reconstitute positive charge on the surface of lysine and increase binding affinity with the negatively charged surface of DNA $(5,6)$. Furthermore, interactions between histone and DNA result in the formation of compacted and inactive chromatin that restrains gene transcription (7-10).

The dysfunction of histone deacetylation is associated with the occurrence and development of liver disease (11). HDACs 
are emerging as next-generation drug targets, thus gaining increasing attention and recognition (12-15). HDAC2 is responsible for the deacetylation of the N-terminal of histone $\mathrm{H} 3$ and $\mathrm{H} 4$, leading to a more compacted chromatin structure and transcriptional gene silencing $(16,17)$. HDAC2 participates in the genesis and development of renal, cardiovascular, neurological and lung disease (18-23). Furthermore, small molecular compounds, peptides and other biological agents that inhibit HDAC2 show potential in the treatment of cancer (24-26), as well as degenerative and inflammatory immune disease (27-29). In particular, evidence has also highlighted the key role of HDAC2 in the pathological process of liver disease (30-32).

The present review introduces gene localization, structural information and biological functions of HDAC2, as well as the pharmacological role of HDAC2, its expression level in a variety of liver diseases and effects on hepatocyte apoptosis and proliferation, liver regeneration, hepatocellular carcinoma (HCC), liver fibrosis and non-alcoholic steatohepatitis (NASH). Finally, a number of selective HDAC2 inhibitors and non-coding (nc)RNAs relevant for HDAC2 expression in liver disease are reviewed (Fig. 1).

\section{HDAC2}

Characterization and classification of HDACs. Histone proteins serve structural and functional roles almost in all nuclear processes $(33,34)$. Histones, DNA and a number of different protein complexes form chromatin to facilitate dynamic changes that occur during DNA replication, cell-cycle progression, transcription process and post-transcription events (35). Changes in chromatin that do not involve a change in DNA sequence are defined as epigenetic modification. One of the earliest known types of chromatin epigenetic modifications is histone acetylation, although its potential role in cell fate determination has not been fully elucidated (36). Acetylation has been widely studied and its potential roles and regulatory mechanisms have been revealed $(37,38)$.

Like HATs, HDACs are rich in structural diversity and serve multiple functions (39), making them potential targets for pharmacological intervention and drug development (40). HDACs are part of a multiprotein family in which each member of HDAC has its own specialized function. In mammals, the HDAC family can be divided into four distinct subfamilies according to their structure, enzyme function, subcellular localization, expression pattern and homology with a typical HDAC in yeast (Table I): Class I (HDACs 1-3 and 8), II (HDACs 4-7, 9 and 10), III [Sirtuins (Sirs/SIRTs)] and IV (HDAC11) (41-44). The class I HDAC family consists of HDAC1-3 and 8, which have a relatively high similarity to HDAC2. They are $\sim 50 \mathrm{kDa}$ in size, are ubiquitously expressed and have homology with yeast reduced potassium dependency $3(37,45,46)$. Class II HDACs comprise HDAC4-7, 9 and 10, which have a high degree of homology to yeast HDA-1 (47-49). They are $120-150 \mathrm{kDa}$ in size and are widely expressed in a tissue-specific manner $(50,51)$. Class II HDACs can be separated into class IIa (HDACs 4, 5, 7 and 9) and IIb (HDACs 6 and 10), depending on the presence of tandem deacetylase domains $(41,52)$. The class III HDACs, also known as Sir2 family, are named for their homology to the yeast Sir2gene. Sir2 family is a highly conservative gene family, including Sirt1-7 (53-55). Among these, Sirt1, 2, 3 and
5 have a common NAD-dependent deacetylase domain, which can catalyze the deacetylation of histone as well as non-histone proteins. By contrast, Sirt 4 and 6 have a NAD ${ }^{+}$-dependent ADP ribosylation domain, which is key for protein ribosylation $(54,55)$. Class III HDACs share little homology with class I and II HDACs, and their enzyme activity is not inhibited by broad-spectrum HDAC inhibitors [such as butyrate, valproic acid, trichostatin A (TSA) or suberoyl anilide hydroxamic acid] (56). The class IV family HDAC11 shares some, but not sufficient, homology with class I and II HDACs $(57,58)$. HDAC11 is enriched in the brain, heart, muscle, kidney and testis in a cell type-specific manner $(48,59)$. Furthermore, class I, II and IV HDACs have a zinc-dependent active site that can be specifically targeted by(compounds containing hydroxamates), such as TSA. As many drugs targeting HDAC isotypes have shown positive effects, HDAC enzymes may represent a novel therapeutic target for liver disease $(2,11)$.

Structure and subcellular location of HDAC2. HDAC2 belongs to class I HDAC family, which is primarily located in the nucleus. HDAC2 is a specific enzyme with high activity and enantioselectivity to histone substrates (60). HDAC2 shares high structural homology and a common catalytic mechanism with other class I HDACs, particularly HDAC1. Similar to other class I HDACs, HDAC2 comprises a conserved deacetylase domain with short amino- and carboxy-terminal extensions, which are key for localization and maintaining their stability and function (48). HDAC1 and HDAC2 have notable amino acid homology. In large-scale gene expression analysis of brain and heart tissue, they affect different target gene sets by forming the same compressor complex (61). The crystal structure of human HDAC2 protein in the presence of hydroxamates has been revealed. The HDAC2 catalytic site is made up of a 'foot pocket', a lipophilic 'tube' and a catalytic $\mathrm{Zn}^{2+} 8 \AA$ deep. More specifically, the 'foot pocket', tightly adjacent to the zinc binding site, is primarily formed by Tyr29, Met35, Phe114 and Leu144. The lipophilic tube, leading from the surface to the zinc binding site, is surrounded by Gly154, Phe155, His183, Phe210 and Leu276 $(62,63)$. Furthermore, the zinc ion is accompanied by Asp181, His183, and Asp269 (62-64). HDAC2 inhibitors typically have a pharmacophore comprising three sectors: A zinc-binding group, a linker portion and a hydrophobic cap group (65-67). Based on molecular docking and virtual screening techniques, a series of compounds with novel skeletal structures have been identified as HDAC inhibitors, and their inhibitory activities and clinical therapeutic effects have been investigated $(68,69)$. HDAC2 is the most thoroughly studied member of the HDAC family, which can be modulated by post-translational modifications, such as phosphorylation (70,71), acetylation (72), ubiquitination (73) and sumoylation (74). In particular, post-translational phosphorylation of HDAC2 negatively regulates its deacetylase activity and serves an active role in chronic inflammation (75). Furthermore, HDAC2 possesses several phosphorylation sites at the C-terminal, which are concentrated on serine residue (76).

\section{Role of HDAC2 in hepatocyte apoptosis and proliferation}

HDAC2 inhibits hepatocyte apoptosis. Due to its anatomical location and complex intersection, the liver is vulnerable to 
Table I. Classification of classic HDACs.

\begin{tabular}{|c|c|c|c|c|c|c|c|}
\hline Class & Co-factors & $\begin{array}{l}\text { Sequence } \\
\text { homology }\end{array}$ & Protein & Size (AA) & $\begin{array}{l}\text { Chromosomal } \\
\text { location }\end{array}$ & $\begin{array}{l}\text { Sub-cellular } \\
\text { localization }\end{array}$ & Tissue expression \\
\hline \multirow[t]{4}{*}{ I } & \multirow[t]{4}{*}{$\mathrm{Zn}^{+}$} & \multirow[t]{4}{*}{ Yeast RPD3 } & HDAC1 & 482 & $1 \mathrm{p} 34$ & Nucleus & Ubiquitous \\
\hline & & & HDAC2 & 488 & $6 q 21$ & Nucleus & Ubiquitous \\
\hline & & & HDAC3 & 428 & $5 q 31$ & Nucleus/cytoplasm & Ubiquitous \\
\hline & & & HDAC8 & 377 & $\mathrm{Xq13}$ & Nucleus & Ubiquitous \\
\hline \multirow[t]{4}{*}{ IIa } & \multirow[t]{4}{*}{$\mathrm{Zn}^{+}$} & \multirow[t]{4}{*}{ Yeast HDA1 } & HDAC4 & 1084 & $2 q 37$ & Nucleus/cytoplasm & Heart, smooth muscle, brain \\
\hline & & & HDAC5 & 1122 & $17 \mathrm{q} 21$ & Nucleus/cytoplasm & Heart, smooth muscle, brain \\
\hline & & & HDAC7 & 952 & $12 \mathrm{q} 13$ & Nucleus/cytoplasm & $\begin{array}{l}\text { Heart, placenta, pancreas, } \\
\text { smooth muscle }\end{array}$ \\
\hline & & & HDAC9 & $\begin{array}{l}1011 / 879 / \\
590\end{array}$ & $7 \mathrm{p} 15-\mathrm{p} 21$ & Nucleus/cytoplasm & Smooth muscle, brain \\
\hline \multirow[t]{2}{*}{$\mathrm{IIb}$} & \multirow[t]{2}{*}{$\mathrm{Zn}^{+}$} & \multirow[t]{2}{*}{ Yeast HDA1 } & HDAC6 & 1215 & Xp11 & Nucleus/cytoplasm & Kidney, liver, heart, pancreas \\
\hline & & & HDAC10 & 669 & $22 q 13$ & Nucleus/cytoplasm & Spleen, kidney, liver \\
\hline \multirow[t]{7}{*}{ III } & \multirow[t]{7}{*}{$\mathrm{NAD}^{+} / \mathrm{NAD}$} & \multirow[t]{7}{*}{ Yeast Sir2 } & SIRT1 & 564 & \multirow[t]{7}{*}{ No data } & Euchromatin & \multirow[t]{7}{*}{ Unknown } \\
\hline & & & SIRT2 & 377 & & Cytoplasm & \\
\hline & & & SIRT3 & 396 & & Mitochondrial & \\
\hline & & & SIRT4 & 320 & & Mitochondrial & \\
\hline & & & SIRT 5 & 308 & & Mitochondrial & \\
\hline & & & SIRT6 & 356 & & Heterochromatin & \\
\hline & & & SIRT7 & 407 & & Nucleolus & \\
\hline IV & $\mathrm{Zn}^{+}$ & $\begin{array}{l}\text { Yeast } \\
\text { RPD3/HDA1 }\end{array}$ & HDAC11 & 347 & $3 \mathrm{p} 25$ & Nucleus & $\begin{array}{l}\text { Heart, smooth muscle, } \\
\text { kidney, brain }\end{array}$ \\
\hline
\end{tabular}

HDAC/HDA, histone deacetylase; RPD3, reduced potassium dependency 3; Sir/SIRT, sirtuin.

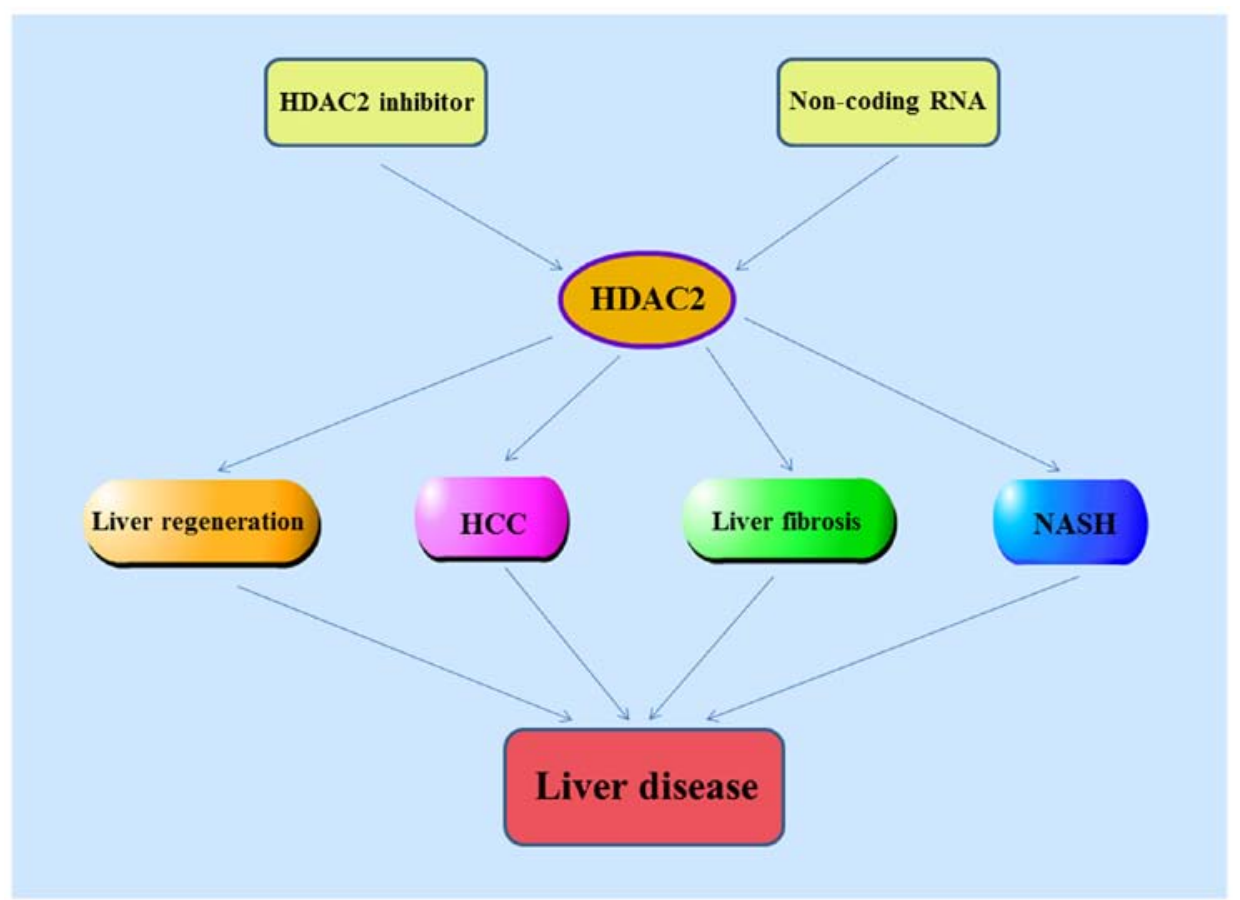

Figure 1. HDAC2 inhibitor and non-coding RNA relevant to HDAC2 expression in liver disease. HDAC2, histone deacetylase 2; HCC, hepatocellular carcinoma; NASH, non-alcoholic steatohepatitis.

a variety of toxic, metabolic, inflammatory and necrotic stimuli $(77,78)$. Hepatocytes are highly sensitive to death receptor-mediated apoptosis due to ubiquitous expression of death receptors in the liver (79). It has been demonstrated 
that the abnormal death of hepatocytes is a key trigger factor for the occurrence and development of both acute and chronic liver disease (77). It is therefore necessary to investigate the underlying pathogenesis and therapeutic targets of liver disease and the expression levels and pharmacological activity of HDAC2. There is increasing evidence that HDAC2 is involved in the regulation of hepatocyte death, thereby implying that HDAC2 serves a key role in the pathogenesis of liver disease $(80,81)$. Here, experimental evidence for the effects of HDAC2 on hepatocyte apoptosis will be discussed.

TGF- $\beta$, a pleiotropic growth factor, has been shown to induce apoptosis in primary rat and AML-12 murine hepatocytes, consequently leading to liver injury and regeneration termination $(80,81)$. Through transfection of HDAC2 RNA interference (RNAi) plasmid, Lei et al (80) found that HDAC2 serves as a significant anti-apoptotic factor in TGF- $\beta 1$-induced apoptosis of AML-12. Lei et al further found that downregulation of HDAC2 significantly induces spontaneous cell apoptosis and increases the apoptotic response following TGF- $\beta 1$ treatment. Moreover, ERK1/2 has been shown to be significantly inhibited in cells transfected with HDAC2i. In HDAC2i-transfected cells, low baseline levels of phosphorylated ERK1/2 were concomitant with decreased TGF- $\beta 1$-induced apoptosis, suggesting that negative regulation of ERK1/2 is associated with the role of HDAC2 in apoptosis. In sum, these findings highlighted that silencing HDAC2 may induce spontaneous apoptosis of AML12 hepatocytes by promoting ERK1/2 expression and pharmacological activity. Taken together, this supports the important physiological role of HDAC2 in hepatocyte apoptosis. The anti-apoptotic effect of HDAC2 overexpression may be a promising therapeutic strategy for treatment of liver disease.

HDAC2 promotes proliferation of hepatocytes. Impaired proliferation of hepatocytes is associated with the occurrence and progression of liver disease (82). However, little is known about the underlying mechanisms that lead to defective hepatocyte proliferation. HDAC2 serves critical roles in cell proliferation and tissues regeneration (83). HDAC2 knockout inhibits proliferation and induces senescence of MCF7 cells by enhancing the binding activity and interaction of p53-DNA (84). HDAC2 deficiency usually results in different cellular phenotypes, suggesting that HDAC2 has a cell-type-specific role that may be relevant to the cell proliferative status (30). Turgeon et al (85) demonstrated that defects in tissue structure and perturbation of microenvironment homeostasis are accompanied by inhibition of cell proliferation when HDAC1/2 is knocked out. There is increasing evidence that HDAC2 promote the proliferation of liver cancer cell lines, although there is no indication of HDAC2 involvement in the proliferation of normal liver cells (86-88). Ler et al (86) found that the combined knock out of HDAC2 and HDAC1 decreases cell proliferation and improves survival of patients with HCC. HDAC2 overexpression is routinely detected in cancer cells, and HDAC2 deficiency and inhibition lead to HCC cell apoptosis (87). The role of HDAC2 in cell proliferation was previously observed in the development of cardiac and B cells; HDAC2 and HDAC1 jointly inhibit cell cycle protein-dependent kinase p21 (WAF1/CIP1) and
p57KIP2 transcription and promote progression from $\mathrm{G}_{1}$ to $\mathrm{S}$ phase (88). By contrast, HDAC2 suppresses transcription of p21WAF1/CIP1 via binding to Sp1-binding site enriched proximal region of the $\mathrm{p} 21 \mathrm{WAF} 1 / \mathrm{CIP} 1$ promoter (89).

\section{HDAC2 in liver disease}

HDAC2 promotes liver regeneration. Liver regeneration is of clinical significance in various types of liver disease $(90,91)$. In the event of massive hepatocyte loss or damage, the intrinsic regenerative capacity of hepatocytes is activated by endogenous molecule-mediated signaling pathways (92). Rapid synchronous compensatory regeneration occurs following 2/3 partial hepatectomy $(\mathrm{PH})$, and regenerated hepatocytes immediately enter the cell cycle and proliferate rapidly, restoring their original quality and function (93). Studies on the deficiency of HDAC2 in mouse liver regeneration have confirmed the key role of HDAC2 in liver regeneration $(94,95)$. Following $\mathrm{PH}$, the liver/body weight ratio is significantly lower in hepatocyte-selective HDAC $2^{-/-}$mice compared with wild-type mice; HDAC $2^{-/-}$mice also show more severe liver damage. Additionally, the expression of HDAC2 gradually increases within 0.5 to 3.0 days in mouse post-hepatectomy livers at an early stage of regeneration. Ki67, a mitotic marker, is decreased by $\sim 30-70 \%$ in HDAC2 knockout mice, subsequently leading to defective mitosis. Decreased cyclinD1 and CDK2 in HDAC2-deficient hepatocytes suggests that HDAC2 liver-specific knockout triggers downregulation of cell cycle proteins and blocks cell cycle progression. Studies have shown that HDAC2 is expressed differently in male and female mice, and HDAC2 can directly bind to the promoter of B-myc $(93,95)$. The expression of B-myc in the female liver is higher than in the male liver, which may be potential mechanism for the significantly slower rate of replication and quality reconstruction of individual female hepatocytes following $\mathrm{PH}$. In conclusion, the altered metabolic pattern in HDAC2 knockout mice is consistent with the well-known regenerative characteristic of hepatocytes. This evidence also confirms a key role for HDAC2 in the metabolic response following PH (Fig. 2).

HDAC2 in liver fibrosis. Liver fibrosis, primarily characterized by excessive accumulation of extracellular matrix proteins, is a worldwide medical problem with increasing annual morbidity $(96,97)$. The majority cases of liver fibrosis arise in the context of various etiology of liver damage, such as chronic viral infections (98), excessive alcohol consumption (99), metabolic disorder (100) or autoimmune disease (101). The regression and improvement of liver fibrosis are primarily attributed to inactivation and apoptosis of activated hepatic stellate cells (HSCs) (102). Notably, emerging evidence has revealed the potential features and roles of HDACs in the progression of liver fibrosis $(103,104)$. It was also reported that several HDACs are involved in the activation of HSCs and the progression of hepatic fibrosis $(105,106)$. In addition, accumulating evidence has highlighted the key role of HDAC2 in the development of renal fibrosis and pulmonary fibrosis $(18,107,108)$. In this regard, it is worth verifying the functional role of HDAC2 in the occurrence and reversal of liver fibrosis. 


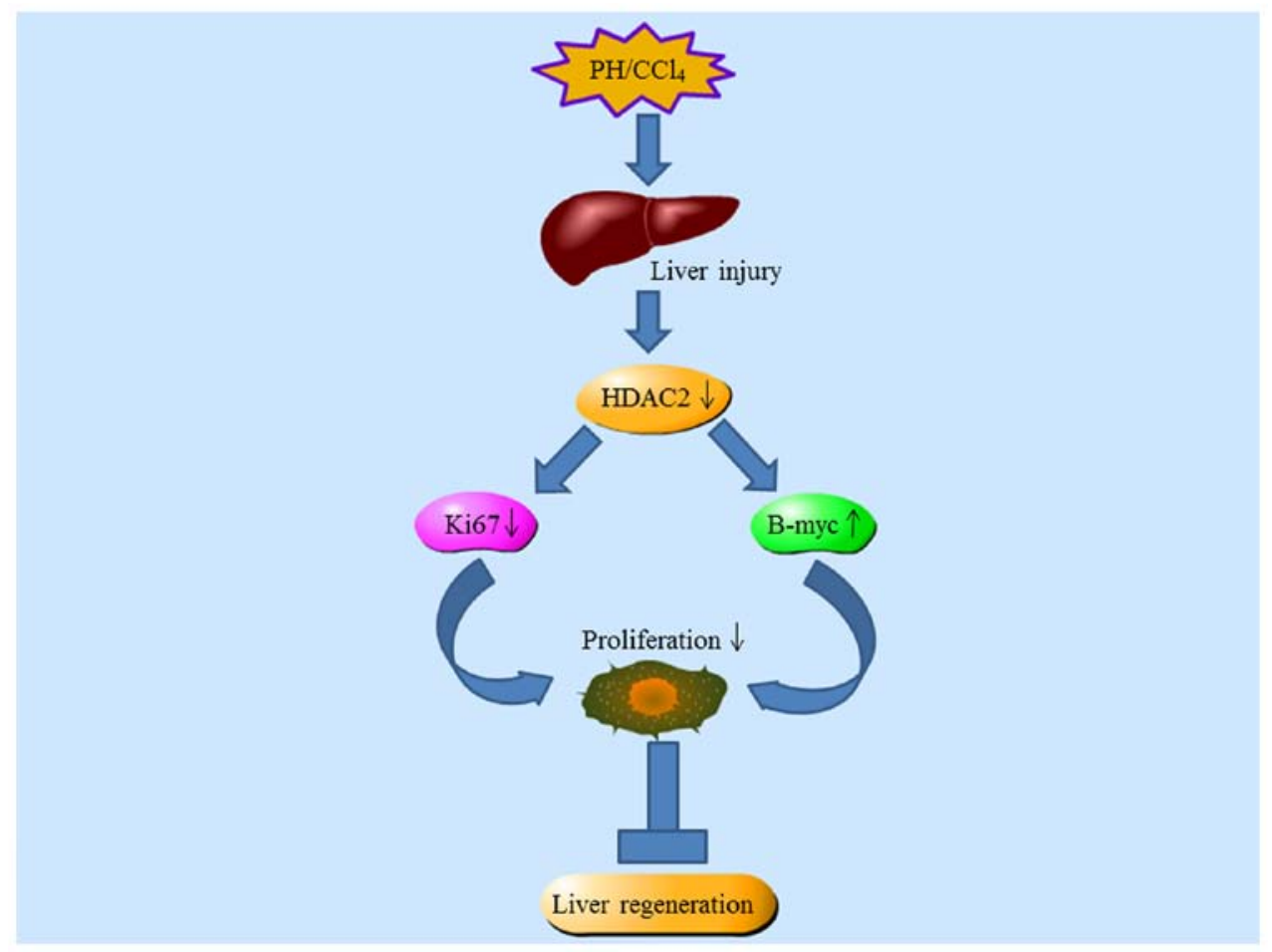

Figure 2. Schematic representation of the role of $\mathrm{HDAC} 2$ in liver regeneration. Following $\mathrm{PH}$ or $\mathrm{CCl}_{4}$ exposure, the expression of $\mathrm{HDAC} 2$ decreases. The loss of HDAC2 inhibits expression of Ki67 and induces expression of B-myc, which results in hepatocyte mitosis defects and impaired liver regeneration. $\mathrm{PH}$, partial hepatectomy; HDAC2, histone deacetylase 2.

In order to reveal the possible association between HDAC2 and liver fibrosis, a $\mathrm{CCl}_{4}$-induced mouse liver fibrosis and its spontaneous reversal model have been successively established (119); this supported the view that aberrant HDAC expression and activity participate in the occurrence and development of liver fibrosis. Expression of HDAC2 is increased during $\mathrm{CCl}_{4}$-induced liver fibrosis and significantly decreased during its reversal. Similarly, the expression of HDAC2 is also significantly increased in human hepatic fibrosis. Exposure of HSC-T6 cells to TGF- $\beta 1$ results in increased HDAC2 expression in a dose- and time-dependent manner. Loss-of-function analyses have confirmed that loss of HDAC2 induces cell cycle arrest and inhibits the expression of collagen $1 \alpha 1$ and $\alpha$-smooth muscle actin protein in HSC-T6 cells activated by TGF- $\beta 1$ (110-112). Mechanistically, it has been widely reported that HDAC2-small interfering (si)RNA leads to increased expression of SMAD7 compared with scramble siRNA-transfected groups $(111,112)$. Collectively, these results suggest that HDAC2 activates HSCs and promotes the occurrence of liver fibrosis by suppressing SMAD7 expression. In conclusion, these findings may demonstrate the role of HDAC2 in the progression and reversal of liver fibrosis, and therefore have significant implications for the development of novel treatment strategies for liver fibrosis (Fig. 3).

HDAC2 in NASH. NASH, a more aggressive form of non-alcoholic fatty liver disease, is pathologically characterized by cell damage, inflammatory cell infiltration and hepatocyte ballooning $(113,115)$. Sustained accumulation of reactive oxygen species (ROS) and resultant oxidative stress, mitochondrial dysfunction and accumulation of triglyceride and lipotoxic metabolites have been identified as contributing factors to NASH (115). To date, there are no current Food and Drug Administration (USA)-approved effective therapies to manage NASH (116). The inhibitory modulation of HDAC2 may contribute to the prevention of NASH (117).

Zhong et al (117) found that CD36 deficiency specifically upregulates monocyte chemotactic protein-1 (MCP-1) expression, thereby aggravating macrophage infiltration and hepatic inflammation. In addition, they also indicated that CD36 deficiency effectively suppresses nuclear HDAC2 expression by decreasing intracellular ROS and increasing the binding of acetyl histone 3 to MCP-1 promoter, which subsequently enhances expression of MCP-1, increases hepatic macrophage infiltration and promotes NASH development. Screening of 11 classic HDACs in CD36 ${ }^{-/}$mouse liver and CD36-deficient hepatocytes also revealed that $\mathrm{CD} 36$ deletion significantly inhibits nuclear expression of HDAC2 in hepatocytes, but not that of other HDACs. Taken together, this indicates that CD36 deficiency in hepatocytes promotes MCP-1 expression by inhibiting nuclear expression of HDAC2. Thus, the loss of CD36 results in decreased ROS levels, which lead to the development of NASH in mice by inhibiting the expression of HDAC2 and promoting that of MCP-1. Overall, maintaining a good balance between nuclear HDAC2 expression and hepatic ROS levels may be a potential novel therapeutic strategy for the prevention of NASH (Fig. 4).

HDAC2 promotes HCC. $\mathrm{HCC}$ is one of the most common types of solid malignancy and is driven by different molecular mechanisms $(118,119)$. Researchers have linked gene expression signatures with the occurrence and prognosis of HCC and investigated gene expression patterns and potential therapeutic targets (120). Evidence suggests that HDAC2 is 


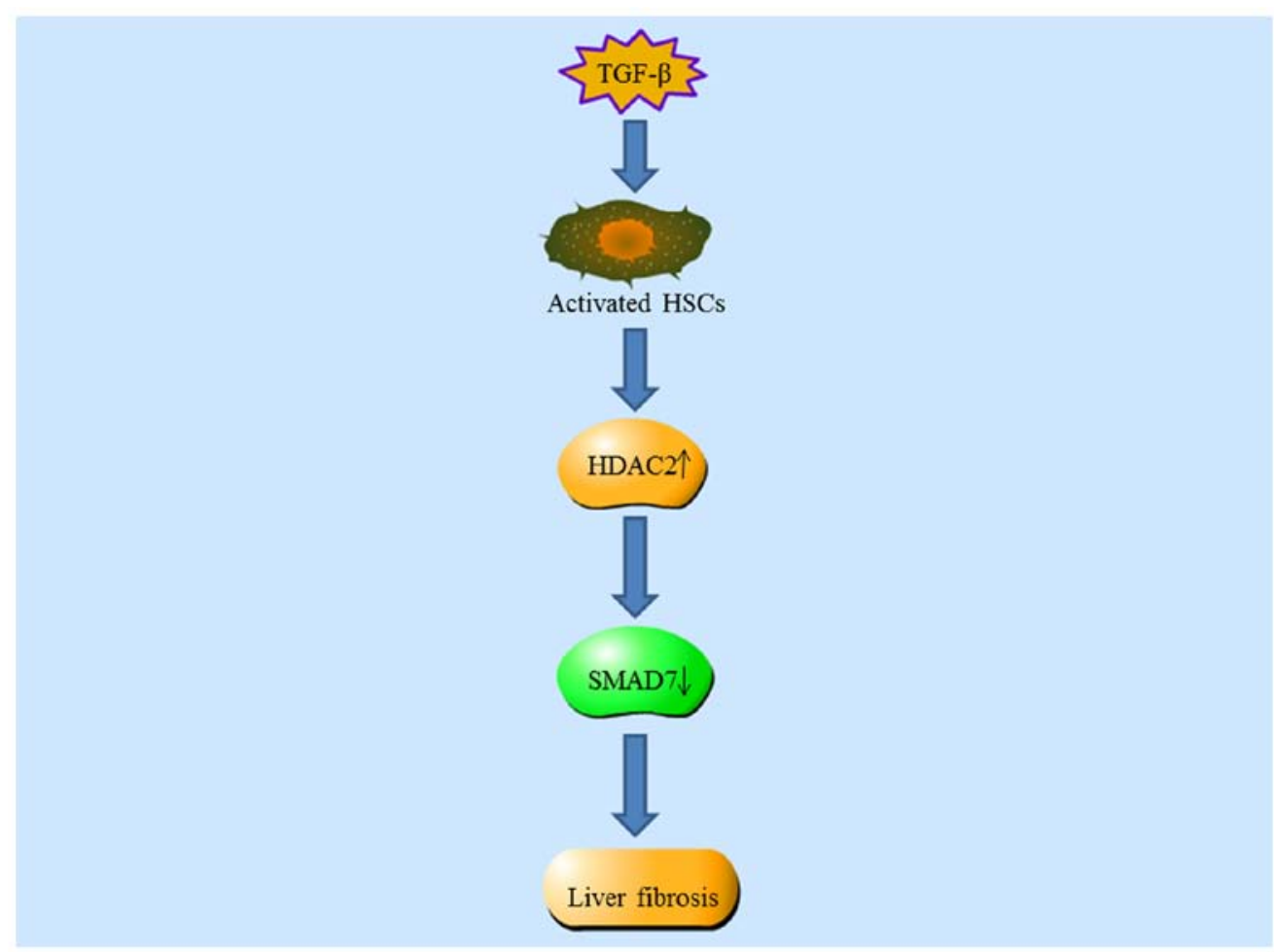

Figure 3. Potential regulatory mechanisms of HDAC2 in liver fibrosis. The expression of HDAC2 protein increases in mice exposed to $\mathrm{CCl}_{4}$ and $\mathrm{HSC}^{-\mathrm{T} 6}$ cells treated with TGF- $\beta$. Furthermore, HDAC2 exerts its key role in HSC activation and liver fibrosis by suppressing the expression of SMAD7, which is a negative modulator in of HSC activation and liver fibrosis. HDAC2, histone deacetylase 2; HSCs, hepatic stellate cells.

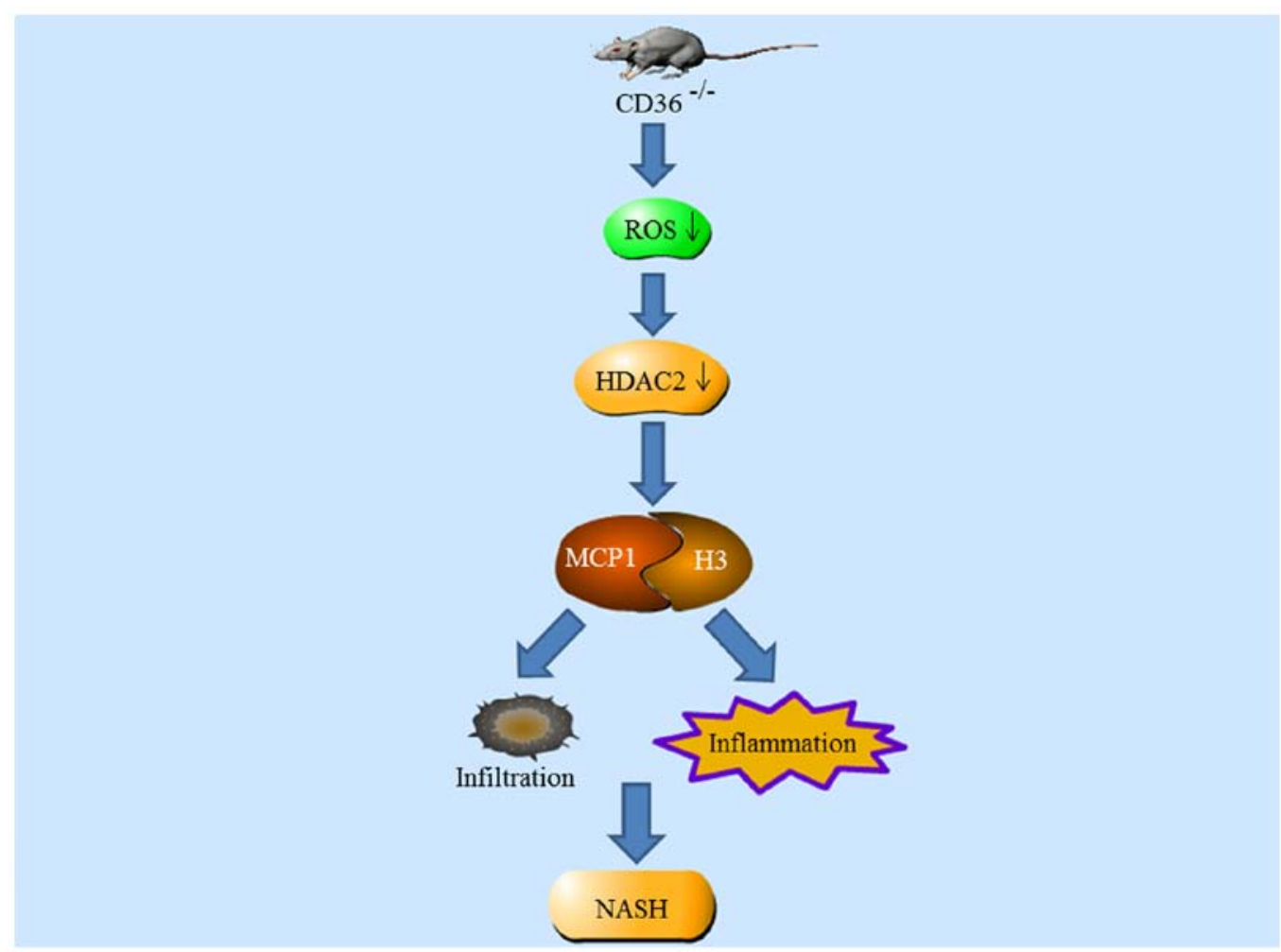

Figure 4. Key roles of HDAC2 in the progression of NASH. In CD36 ${ }^{-/}$mice, CD36 deficiency blocks hepatic HDAC2 by decreasing ROS levels, and increases acetyl histone3 binding to MCP-1, thus enhancing expression of MCP-1, increasing hepatic macrophage infiltration and promoting NASH development. HDAC2, histone deacetylase 2; NASH, non-alcoholic steatohepatitis; ROS, reactive oxygen species; MCP-1, monocyte chemotactic protein-1.

overexpressed in tumors, and HDAC2 downregulation leads to high expression levels of cell cycle circuit elements, including
p21WAF1/Cip1, which is a well-characterized regulatory factor that serves a key role in cell senescence $(121,122)$. With 


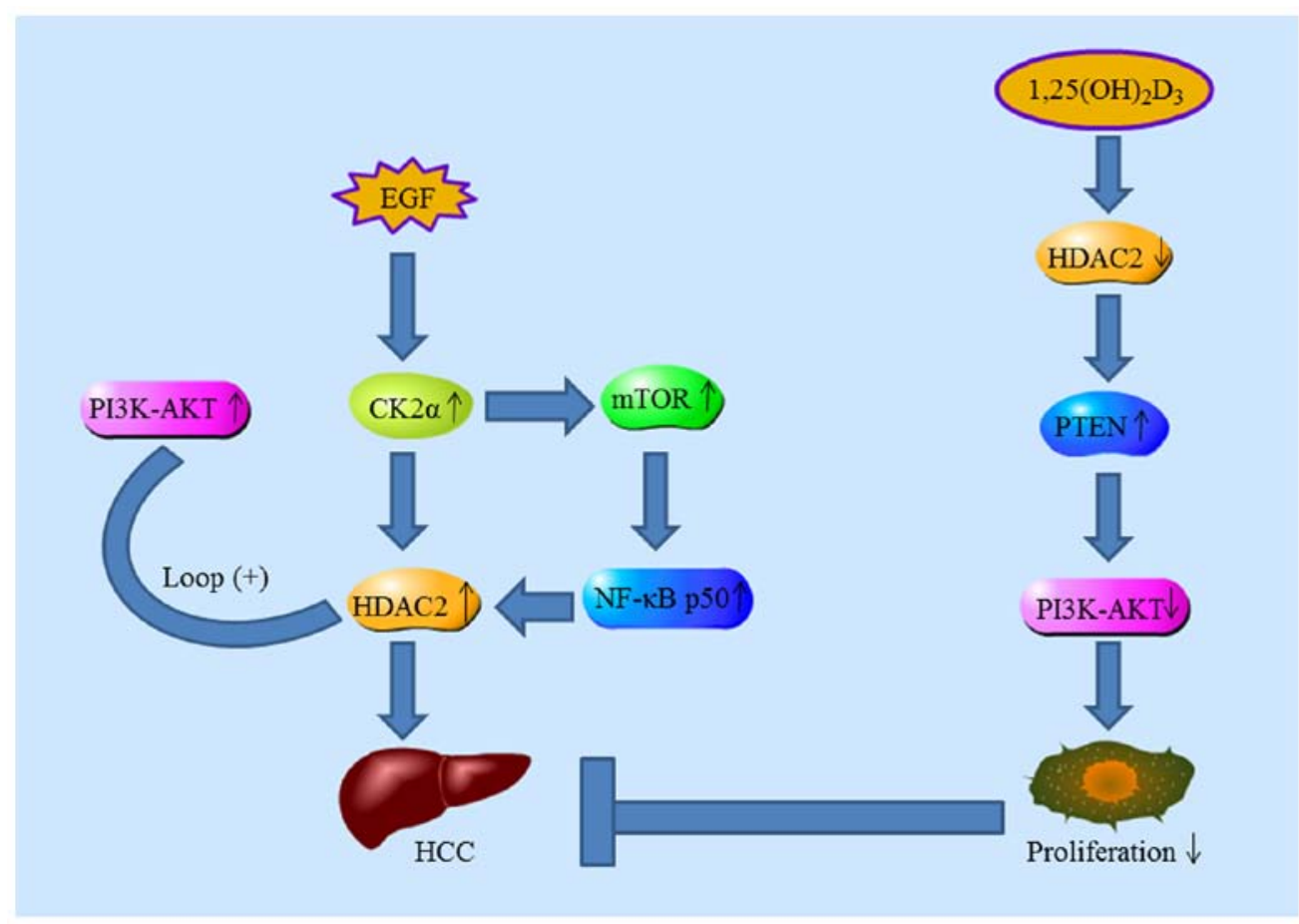

Figure 5. Schematic representation of the role of HDAC2 in HCC. Treatment with EGF increases CK2 $\alpha$ expression and phosphorylation of mTOR and AKT, inducing expression of HDAC2 in HCC. In addition, elevated expression of HDAC2 triggers a positive feedback loop of AKT phosphorylation via transcriptional modulation of phosphoinositide signaling molecules. Furthermore, $1,25(\mathrm{OH})_{2} \mathrm{D}_{3}$ inhibits the growth of HCC cells via downregulating HDAC2-mediated PTEN upregulation, and upregulating p21 (WAFI/CIP1), AKT deactivation and inhibition of the PI3K/AKT signaling pathway. HDAC2, histone deacetylase 2; $\mathrm{CK} 2 \alpha$, casein kinase II; HCC, hepatocellular carcinoma.

regard to liver cancer, HDAC2 promotes proliferation, and its aberrant expression may be a prognostic indicator of $\mathrm{HCC}(86)$.

A study found that HDAC2 overexpression is associated with poor survival of patients with low-grade and early-stage tumors, suggesting that HDAC2 is an independent and reliable predictor of survival of patients with HCC (123). Noh et al (89) assessed the tumorigenic potential of HDAC2, evaluated abnormal HDAC2 expression and investigated its regulatory mechanism in HCC; abnormal regulation of HDAC2 served a key role in HCC progression by regulating cell cycle regulatory components at the transcriptional level. Their data also showed that HDAC2 overexpression was not associated with Wnt and c-myc signaling pathways, which play an important role in malignant cell proliferation. Kim et al (124) investigated the underlying mechanism of HDAC2 in tumorigenesis; increased expression of casein kinase II $(\mathrm{CK} 2 \alpha)$ was positively correlated with HDAC2. They proposed a regulatory mechanism whereby increased HDAC2 expression in HCC is primarily caused by the activation of $\mathrm{CK} 2 \alpha / \mathrm{AKT}$ pathways mediated by EGF. Lee et al (108) indicated that systemic delivery of HDAC2 siRNA encapsulated in lipid nanoparticles is sufficient to inhibit HCC progression. In addition, mTORC1 activation and $\mathrm{NF}-\kappa \mathrm{B}$ p50 nuclear translocation are essential for the transcriptional activation of oncogenic HDAC2 in HCC (125). Furthermore, $1,25(\mathrm{OH})_{2} \mathrm{D}_{3}$ inhibits the progression of HCC by downregulating HDAC2 $(126,127)$. Consistently, Wang et al (128) also found that high levels of HDAC2 expression are negatively correlated with PTEN expression in HCC patients with poor prognosis (Fig. 5).

Merck60 selectively inhibits HDAC1 and HDAC2, thereby increasing histone acetylation and disrupting core gene regulatory architecture in rhabdomyosarcoma (129). Methot et al (130) investigated novel selective HDAC1/HDAC2 inhibitors (SHI-1:2), which incorporate a biaryl zinc-binding motif into a nicotinyl scaffold; the optimized SHI-1:2 structure exhibited notable inhibitory activity against HDAC1 and HDAC2, and its specific selectivity for HDAC1/HDAC2 was 100 times higher than that for other HDACs (131). N-(2-amino-5-substituted phenyl) benzamide significantly induced HCT116 cell death by specifically targeting HDAC2 (62). In addition, the effects of $\mathrm{C} 15$ urushiol and its triazole derivatives on the apoptosis of liver cancer cells have been qualitatively and quantitatively verified (132). Venturelli et al (133) reported that 6- and 8-prenylnaringenin enter into the 'foot pocket' of HDAC2 and combine with zinc ion of their catalytic center, subsequently inhibiting excessive proliferation of melanoma cells. N-[4-(Hydrazinecarbonyl)phenyl]-3,5,6-trimethylpyrazine-2-carboxamide exhibits notable anticancer activity in vivo $\left(\mathrm{IC}_{50}=1.60 \mu \mathrm{M}\right)$ (134) Among squaramide-based derivatives, the lead compound 42 exhibits good druggability by specifically inhibiting HDAC2 (67). Isopropyl derivative 5 and tert-butyl derivative 6 , is which derived from the lead compound NSC746457, exhibit a significantly inhibitory effect on HDAC2 (63). Novel indazole and pyrazolo(3,4-b) pyridine derivatives have been designed and synthesized via fragment-based virtual screening; biological evaluation showed that compounds $15 \mathrm{k}$ and $15 \mathrm{~m}$ possess distinctly inhibitory effect towards HDAC2 (66). Rosmarinic acid has been demonstrated to downregulate HDAC2 expression, subsequently leading to cell cycle arrest and apoptosis (135). $\mathrm{N}$-(2-aminophenyl)-4-[(4-fluorophenoxy)methyl] benzamide 
Table II. Lead compounds of potential histone deacetylase 2 inhibitors.

\begin{tabular}{|c|c|c|c|c|}
\hline Inhibitor & Function & $\mathrm{IC}_{50}, \mathrm{nM}$ & Analysis method & (Refs.) \\
\hline Compound 12 & Anticancer & 44.0 & SAR & (136) \\
\hline Compound 5/8 & Anticancer & $27.0 / 39.0$ & SAR & $(59)$ \\
\hline K560 & Neuroprotection & 520.0 & VS & (138) \\
\hline Compound $4 \mathrm{~b}$ & ND & 40.6 & SAR & $(87)$ \\
\hline RH01652 & Prevent AD & ND & MDs-QC & (139) \\
\hline BRD8430 & $\begin{array}{l}\text { Neuroblastoma } \\
\text { differentiation }\end{array}$ & ND & HTS & (140) \\
\hline $\begin{array}{l}\text { Eight hits urushiol } \\
\text { derivatives }\end{array}$ & ND & ND & PM-VS & (141) \\
\hline C15 Triene & ND & ND & MD-MDs-VS & $(61)$ \\
\hline Triazole & Anticancer & ND & SAR-MD & (143) \\
\hline ST088357 & ND & 16870.0 & Scaffold-Merging HQ & (148) \\
\hline 6-PN/8-PN & Anticancer & ND & SAR & (145) \\
\hline Compound $4 \mathrm{~g} / 6 \mathrm{c} / 6 \mathrm{~g}$ & ND & $130.0 / 160.0 / 580.0$ & MD & (146) \\
\hline LAQ824 & ND & 3.0 & MD & (147) \\
\hline Compound 7a & Anticancer & 53.7 & QSAR & (148) \\
\hline $\begin{array}{l}\text { Squaramide-based } \\
\text { hydroxamic acids }\end{array}$ & Anticancer & ND & SAR & $(64)$ \\
\hline ID5/TD6 & Anticancer & $22.0 / 18.0$ & Click-chemistry/MD & $(60)$ \\
\hline Compound $15 \mathrm{k} / 15 \mathrm{~m}$ & Anticancer & $4.2 / 3.6$ & VS-MD & $(63)$ \\
\hline Rosmarinic acid & Anticancer & ND & Activity screening & (149) \\
\hline Compound 12a & Anticancer & ND & MD-SAR & $(62)$ \\
\hline Compounds12g/12h & Anticancer & 205.0/144.0 & SAR & (65) \\
\hline
\end{tabular}

ND, no description available; SAR, structure-activity relationship; VS, virtual screening; MDs, molecular dynamics; QC, quantum chemistry; HTS, high-throughput screening; PM, pharmacophore modeling; MD, molecular docking; HQ, hybrid query; QSAR, quantitative SAR.

exhibits antitumor activity by inhibiting $\mathrm{HDAC} 2$ at an $\mathrm{IC}_{50}$ of $3.84 \mu \mathrm{M}(65)$. In addition, a series of 2-aminobenzamide-based compounds exhibit highly inhibitory effects on solid cancer cell lines and low cytotoxicity against normal cells (Table II) (68).

ncRNAs mediate HDAC2 expression at the posttranscriptional level $(136,137)$. A meta-analysis of 1,258 HCC samples showed that downregulation of microRNA (miRNA or $\mathrm{miR}$ )-100-5p contributes to the progression and prognosis of HCC by negatively regulating HDAC2 expression (138). Noh et al (87) found that miR-145 functions as a tumor suppressor by directly targeting HDAC2 in liver cancer. In addition, another study demonstrated that miR-31 significantly decreases HDAC2 expression by suppressing mRNA translation in HCC cells (139). In sum, these results suggest that promotion or suppression of certain miRNAs cause aberrant expression of HDAC2, which be involved in HCC tumorigenesis. Dai et al (140) found that long ncRNA SNHG15 upregulates HDAC2 expression by sponging miR-490-3p, which further promotes HCC progression.

In summary, these results demonstrate that HDAC2 possesses carcinogenic properties. These studies also suggest that the development of novel compounds or ncRNAs may be a promising therapeutic modality for liver cancer by selectively targeting HDAC2.

\section{Conclusion}

Epigenetic modifications serve prime regulatory roles in genetic events, such as transcriptional activation and silencing (141). The effects of epigenetic modifications have been recognized, although their specific roles may still be controversial. Histone acetylation contributes to gene expression, while histone deacetylation leads to suppression of gene transcription (142). Studies have shown that relative levels of histone acetylation and deacetylation are of significance for the regulation of pathophysiological processes, including proliferation, cell-cycle progression, differentiation, immune evasion, inflammatory lesion, apoptosis and death (143-145). Pharmacological inhibition of HDAC activity or expression alters chromatin acetylation levels, subsequently confusing boundaries between transcriptionally active and quiescent chromatin (146-148).

The increasing incidence of liver disease requires novel effective therapeutic interventions. HDAC2 exhibits attractive pharmacological effects in hepatocyte loss or injury, HCC and NASH by modulating hepatocyte death and regulating cell cycle components. In the past decades, researchers have characterized HDAC classification, structure and subcellular localization $(47-50,52,54)$. The malignant or beneficial role of HDAC2 in liver fibrosis, non-alcoholic fatty liver disease and 
liver cancer has been revealed. Nonetheless, the mechanism of HDAC2 in the development of liver disease has not been elucidated and more investigations are needed in future. In summary, these properties of HDAC2 make it an appealing therapeutic target by regulating expression of HDAC 2 and HDAC2-dependent signaling pathways.

HDAC2 presents favorable characteristics as a potential drug target. Consequently, pharmacological agents that inhibit HDAC2 may be a prospective treatment for liver ailments. However, the few known HDAC2 inhibitors are broad spectrum inhibitors that simultaneously inhibit several members of HDACs family and thus may have more potential adverse side effects. Therefore, it is necessary to develop novel HDAC2 inhibitors with higher targeting selectivity. High homology and cellular co-localization of multiple HDACs makes development and use of HDAC2 inhibitors difficult. The expression and pharmacological activity of HDAC2 is important for the prediction, diagnosis and prognosis of liver disease. $\mathrm{NF}-\kappa \mathrm{B}$, c-Myc, Sp1 and Sp3 can bind to the HDAC2 promoter, thereby augmenting HDAC2 transcription (149-151). These findings suggest that the HDAC2 promoter may also be a potential target for pharmacological intervention.

The present study reviewed the specific roles of HDAC2 and the potential application of HDAC2 inhibitors in liver disease. Increasing evidence has highlighted the key role of HDAC2 in the occurrence and development of liver disease and demonstrated that HDAC2 inhibitor therapy may be a therapeutic approach. Better understanding of the potential roles and regulatory mechanisms of HDAC2 in liver disease may improve the ability to predict the pace of liver disease progression and exploit specific targeted therapeutic strategies.

\section{Acknowledgements}

Not applicable.

\section{Funding}

The present study was supported by the National Natural Science Foundation of China (grant no. 81770609).

\section{Availability of data and materials}

Not applicable.

\section{Authors' contributions}

YRL, JL and JQW conceived and designed the study and wrote the manuscript. ZGH, RNC and XC prepared the figures. DCZ and HXY prepared the tables. QX, XRW and HYZ revised the manuscript. All authors read and approved the final version of the manuscript. Data authentication is not applicable.

\section{Ethics approval and consent to participate}

Not applicable.

\section{Patient consent for publication}

Not applicable.

\section{Competing interests}

The authors declare that they have no competing interests.

\section{References}

1. Cai C, Yu H, Huang G, Du X, Yu X, Zhou Y and Shen W: Histone modifications in fatty acid synthase modulated by carbohydrate responsive element binding protein are associated with non-alcoholic fatty liver disease. Int J Mol Med 42: 1215-1228, 2018

2. Ferriero R, Nusco E, De Cegli R, Carissimo A, Manco G and Brunetti-Pierri N: Pyruvate dehydrogenase complex and lactate dehydrogenase are targets for therapy of acute liver failure. J Hepatol 69: 325-335, 2018.

3. Kanyal A, Rawat M, Gurung P, Choubey D, Anamika K and Karmodiya K: Genome-wide survey and phylogenetic analysis of histone acetyltransferases and histone deacetylases of Plasmodium falciparum. FEBS J 285: 1767-1782, 2018.

4. Berger SL: The complex language of chromatin regulation during transcription. Nature 447: 407-412, 2007.

5. Khangura RK, Bali A, Jaggi AS and Singh N: Histone acetylation and histone deacetylation in neuropathic pain: An unresolved puzzle? Eur J Pharmacol 795: 36-42, 2017.

6. Kouzarides T: Chromatin modifications and their function. Cell 128: 693-705, 2007.

7. Leipe DD and Landsman D: Histone deacetylases, acetoin utilization proteins and acetylpolyamine amidohydrolases are members of an ancient protein superfamily. Nucleic Acids Res 25: 3693-3697, 1997.

8. West AC and Johnstone RW: New and emerging HDAC inhibitors for cancer treatment. J Clin Invest 124: 30-39, 2014.

9. Ibi D and Gonzalez-Maeso J: Epigenetic signaling in schizophrenia. Cell Signal 27: 2131-2136, 2015.

10. Levenson JM, O'Riordan KJ, Brown KD, Trinh MA, Molfese DL and Sweatt JD: Regulation of histone acetylation during memory formation in the hippocampus. J Biol Chem 279: 40545-40559, 2004.

11. Cao YN, Xue Y, Xue L, Jiang X, Wang X, Zhang Z, Yang J, Lu J, Zhang C, Wang W and Ning G: Hepatic menin recruits SIRT1 to control liver steatosis through histone deacetylation. J Hepatol 59: 1299-1306, 2013.

12. Simões-Pires C, Zwick V, Nurisso A, Schenker E, Carrupt PA and Cuendet M: HDAC6 as a target for neurodegenerative diseases: What makes it different from the other HDACs? Mol Neurodegener 8: 7, 2013.

13. Kim HJ and Bae SC: Histone deacetylase inhibitors: Molecular mechanisms of action and clinical trials as anti-cancer drugs. Am J Transl Res 3: 166-179, 2011.

14. Glauben R, Batra A, Stroh T, Erben U, Fedke I, Lehr HA, Leoni F, Mascagni P, Dinarello CA, Zeitz M and Siegmund B: Histone deacetylases: Novel targets for prevention of colitis-associated cancer in mice. Gut 57: 613-622, 2008.

15. Dokmanovic M, Clarke C and Marks PA: Histone deacetylase inhibitors: Overview and perspectives. Mol Cancer Res 5: 981-989, 2007.

16. Marchion DC, Bicaku E, Turner JG, Schmitt ML, Morelli DR and Munster PN: HDAC2 regulates chromatin plasticity and enhances DNA vulnerability. Mol Cancer Ther 8: 794-801, 2009.

17. Jahan S, Sun JM, He S and Davie JR: Transcription-dependent association of HDAC2 with active chromatin. J Cell Physiol 233: 1650-1657, 2018.

18. Noh H, Oh EY, Seo JY, Yu MR, Kim YO, Ha H and Lee HB: Histone deacetylase-2 is a key regulator of diabetes- and transforming growth factor-betal-induced renal injury. Am J Physiol Renal Physiol 297: F729-F739, 2009.

19. Yang FQ, Liu M, Yang FP, Che J, Li W, Zhai W, Wang GC, Zheng JH and Li X: VPA inhibits renal cancer cell migration by targeting HDAC2 and down-regulating HIF-1 $\alpha$. Mol Biol Rep 41: 1511-1518, 2014.

20. Fritzsche FR, Weichert W, Roske A, Gekeler V, Beckers T, Stephan C, Jung K, Scholman K, Denkert C, Dietel M and Kristiansen G: Class I histone deacetylases 1, 2 and 3 are highly expressed in renal cell cancer. BMC Cancer 8: 381, 2008.

21. Shang L, Pin L, Zhu S, Zhong X, Zhang Y, Shun M, Liu Y and Hou M: Plantamajoside attenuates isoproterenol-induced cardiac hypertrophy associated with the HDAC2 and AKT/GSK-3 $\beta$ signaling pathway. Chem Biol Interact 307: 21-28, 2019. 
22. Datta M, Staszewski O, Raschi E, Frosch M, Hagemeyer N, Tay TL, Blank T, Kreutzfeldt M, Merkler D, Ziegler-Waldkirch S, et al: Histone deacetylases 1 and 2 regulate microglia function during development, homeostasis, and neurodegeneration in a context-dependent manner. Immunity 48: 514-529 e6, 2018

23. Bin YF, Wu LJ, Sun XJ, Liang Y, Bai J, Zhang JQ, Li MH, Zhong XN, Liang YJ and He ZY: Expression of GR- $\alpha$ and HDAC2 in steroid-Sensitive and steroid-Insensitive interstitial lung disease. Biomed Pharmacother 118: 109380, 2019.

24. Mahady L, Nadeem M, Malek-Ahmadi M, Chen K, Perez SE and Mufson EJ: HDAC2 dysregulation in the nucleus basalis of Meynert during the progression of Alzheimer's disease. Neuropathol Appl Neurobiol 45: 380-397, 2019.

25. Lin CL, Tsai ML, Lin CY, Hsu KW, Hsieh WS, Chi WM, Huang LC and Lee CH: HDAC1 and HDAC2 double knockout triggers cell apoptosis in advanced thyroid cancer. Int $\mathrm{J}$ Mol Sci 20: 454, 2019 .

26. Stojanovic N, Hassan Z, Wirth M, Wenzel P, Beyer M, Schäfer C, Brand P, Kroemer A, Stauber RH, Schmid RM, et al: HDAC1 and HDAC2 integrate the expression of p53 mutants in pancreatic cancer. Oncogene 36: 1804-1815, 2017.

27. Tang W, Zhou W, Xiang L, Wu X, Zhang P, Wang J, Liu G, Zhang W, Peng Y, Huang X, et al: The p300/YY1/miR-500a-5p/ HDAC2 signalling axis regulates cell proliferation in human colorectal cancer. Nat Commun 10: 663, 2019.

28. Lai T, Wu M, Zhang C, Che L, Xu F, Wang Y, Wu Y, Xuan N, Cao C, Du X, et al: HDAC2 attenuates airway inflammation by suppressing IL-17A production in HDM-challenged mice. Am J Physiol Lung Cell Mol Physiol 316: L269-L279, 2019.

29. Barnes PJ: Corticosteroid resistance in patients with asthma and chronic obstructive pulmonary disease. J Allergy Clin Immunol 131: 636-645, 2013

30. Wilting RH, Yanover E, Heideman MR, Jacobs H, Horner J, van der Torre J, DePinho RA and Dannenberg JH: Overlapping functions of Hdac1 and Hdac2 in cell cycle regulation and haematopoiesis. EMBO J 29: 2586-2597, 2010

31. Wang Y, Yang F, Jiao FZ, Chen Q, Zhang WB, Wang LW and Gong ZJ: Modulations of histone deacetylase 2 offer a protective effect through the mitochondrial apoptosis pathway in acute liver failure. Oxid Med Cell Longev 2019: 8173016, 2019.

32. Wu J, Zhu P, Lu T, Du Y, Wang Y, He L, Ye B, Liu B, Yang L, Wang J, et al: The long non-coding RNA LncHDAC2 drives the self-renewal of liver cancer stem cells via activation of Hedgehog signaling. J Hepatol 70: 918-929, 2019.

33. Verdone L, Agricola E, Caserta M and Di Mauro E: Histone acetylation in gene regulation. Brief Funct Genomic Proteomic 5: 209-221, 2006

34. Millard CJ, Fairall L, Ragan TJ, Savva CG and Schwabe JWR The topology of chromatin-binding domains in the NuRD deacetylase complex. Nucleic Acids Res 48: 12972-12982, 2020.

35. Verdone L, Caserta M and Di Mauro E: Role of histone acetylation in the control of gene expression. Biochem Cell Biol 83 344-353, 2005

36. Brownell JE, Zhou J, Ranalli T, Kobayashi R, Edmondson DG, Roth SY and Allis CD: Tetrahymena histone acetyltransferase A: A homolog to yeast Gen5p linking histone acetylation to gene activation. Cell 84: 843-851, 1996.

37. Kurdistani SK and Grunstein M: Histone acetylation and deacetylation in yeast. Nat Rev Mol Cell Biol 4: 276-284, 2003.

38. Wang D, Kon N, Lasso G, Jiang L, Leng W, Zhu WG, Qin J, Honig B and $\mathrm{Gu}$ W: Acetylation-regulated interaction between p53 and SET reveals a widespread regulatory mode. Nature 538 $118-122,2016$

39. Wang Z, Zang C, Cui K, Schones DE, Barski A, Peng W and Zhao K: Genome-wide mapping of HATs and HDACs reveals distinct functions in active and inactive genes. Cell 138: 1019-1031, 2009.

40. Abel T and Zukin RS: Epigenetic targets of HDAC inhibition in neurodegenerative and psychiatric disorders. Curr Opin Pharmacol 8: 57-64, 2008.

41. de Ruijter AJ, van Gennip AH, Caron HN, Kemp S and van Kuilenburg AB: Histone deacetylases (HDACs): Characterization of the classical HDAC family. Biochem. J 370 (Pt 3): 737-749, 2003

42. Gregoretti IV, Lee YM and Goodson HV: Molecular evolution of the histone deacetylase family: Functional implications of phylogenetic analysis. J Mol Biol 338: 17-31, 2004.

43. Kiweler N, Brill B, Wirth M, Breuksch I, Laguna T, Dietrich C, Strand S, Schneider G, Groner B, Butter F, et al: The histone deacetylases HDAC1 and HDAC2 are required for the growth and survival of renal carcinoma cells. Arch Toxicol 92: 2227-2243, 2018.
44. Bush EW and McKinsey TA: Protein acetylation in the cardiorenal axis: The promise of histone deacetylase inhibitors. Circ Res 106: 272-284, 2010

45. Yang XJ and Seto E: The Rpd3/Hda1 family of lysine deacetylases: From bacteria and yeast to mice and men. Nat Rev Mol Cell Biol 9: 206-218, 2008.

46. Yang WM, Tsai SC, Wen YD, Fejer G and Seto E: Functional domains of histone deacetylase-3. J Biol Chem 277: 9447-9454, 2002.

47. Martin M,Kettmann R and Dequiedt F: Class IIa histone deacetylases: Regulating the regulators. Oncogene 26: 5450-5467, 2007.

48. Haberland M, Montgomery RL and Olson EN: The many roles of histone deacetylases in development and physiology: Implications for disease and therapy. Nat Rev Genet 10: 32-42, 2009.

49. Guardiola AR and Yao TP: Molecular cloning and characterization of a novel histone deacetylase HDAC10. J Biol Chem 277: 3350-3356, 2002.

50. Grozinger CM, Hassig CA and Schreiber SL: Three proteins define a class of human histone deacetylases related to yeast Hda1p. Proc Natl Acad Sci USA 96: 4868-4873, 1999.

51. Marks PA and Breslow R: Dimethyl sulfoxide to vorinostat: Development of this histone deacetylase inhibitor as an anticancer drug. Nat Biotechnol 25: 84-90, 2007.

52. Johnstone RW: Histone-deacetylase inhibitors: Novel drugs for the treatment of cancer. Nat Rev Drug Discov 1: 287-299, 2002.

53. Michan S and Sinclair D: Sirtuins in mammals: Insights into their biological function. Biochem J 404: 1-13, 2007.

54. Abbas A and Gupta S: The role of histone deacetylases in prostate cancer. Epigenetics 3: 300-309, 2008.

55. Yamamoto H, Schoonjans K and Auwerx J: Sirtuin functions in health and disease. Mol Endocrinol 21: 1745-1755, 2007.

56. Xu WS, Parmigiani RB and Marks PA: Histone deacetylase inhibitors: Molecular mechanisms of action. Oncogene 26: 5541-5552, 2007.

57. Gao L, Cueto MA, Asselbergs F and Atadja P: Cloning and functional characterization of HDAC11, a novel member of the human histone deacetylase family. J Biol Chem 277: 25748-25755, 2002.

58. Verdin E and Ott M: 50 years of protein acetylation: From gene regulation to epigenetics, metabolism and beyond. Nat Rev Mol Cell Biol 16: 258-264, 2015.

59. Gong F and Miller KM: Mammalian DNA repair: HATs and HDACs make their mark through histone acetylation. Mutat Res 750: 23-30, 2013.

60. Brunmeir R, Lagger S and Seiser C: Histone deacetylase HDAC1/HDAC2-controlled embryonic development and cell differentiation. Int J Dev Biol 53: 275-289, 2009.

61. Montgomery RL, Hsieh J, Barbosa AC, Richardson JA and Olson EN: Histone deacetylases 1 and 2 control the progression of neural precursors to neurons during brain development. Proc Natl Acad Sci USA 106: 7876-7881, 2009.

62. Bressi JC, Jennings AJ, Skene R, Wu Y, Melkus R, De Jong R, O'Connell S, Grimshaw CE, Navre $M$ and Gangloff AR: Exploration of the HDAC2 foot pocket: Synthesis and SAR of substituted N-(2-aminophenyl)benzamides. Bioorg Med Chem Lett 20: 3142-3145, 2010.

63. Hou J, Feng C, Li Z, Fang Q, Wang H, Gu G, Shi Y, Liu P, Xu F, Yin Z, et al: Structure-based optimization of click-based histone deacetylase inhibitors. Eur J Med Chem 46: 3190-3200, 2011

64. Zhou H, Wang C, Ye J, Chen H and Tao R: Design, virtual screening, molecular docking and molecular dynamics studies of novel urushiol derivatives as potential HDAC2 selective inhibitors. Gene 637: 63-71, 2017.

65. Xie R, Yao Y, Tang P, Chen G, Liu X, Yun F, Cheng C, Wu X and Yuan Q: Design, synthesis and biological evaluation of novel hydroxamates and 2-aminobenzamides as potent histone deacetylase inhibitors and antitumor agents. Eur J Med Chem 134: 1-12, 2017.

66. Liu J,Zhou J, He F, Gao L, Wen Y, Gao L, Wang P, Kang D and Hu L: Design, synthesis and biological evaluation of novel indazole-based derivatives as potent HDAC inhibitors via fragment-based virtual screening. Eur J Med Chem 192: 112-189, 2020.

67. Fournier JF, Bhurruth-Alcor Y, Musicki B, Aubert J, Aurelly M, Bouix-Peter C, Bouquet K, Chantalat L, Delorme M, Drean B, et al: Squaramides as novel class I and IIB histone deacetylase inhibitors for topical treatment of cutaneous t-cell lymphoma. Bioorg Med Chem Lett 28: 2985-2992, 2018.

68. Yun F, Cheng C, Ullah S, He J, Zahi MR and Yuan Q: Thioether-based 2-aminobenzamide derivatives: Novel HDAC inhibitors with potent in vitro and in vivo antitumor activity. Eur J Med Chem 176: 195-207, 2019. 
69. Alsawalha M, Rao Bolla S, Kandakatla N, Srinivasadesikan V, Veeraraghavan VP and Surapaneni KM: Molecular docking and ADMET analysis of hydroxamic acids as HDAC2 inhibitors. Bioinformation 15: 380-387, 2019.

70. Ford J, Ahmed S, Allison S, Jiang M and Milner J: JNK2dependent regulation of SIRT1 protein stability. Cell cycle 7 : 3091-3097, 2008

71. Sun JM, Chen HY and Davie JR: Differential distribution of unmodified and phosphorylated histone deacetylase 2 in chromatin. J Biol Chem 282: 33227-33236, 2007.

72. Ashktorab H, Belgrave K, Hosseinkhah F, Brim H, Nouraie M, Takkikto M, Hewitt S, Lee EL, Dashwood RH and Smoot D: Global Histone H4 Acetylation and HDAC2 expression in colon adenoma and carcinoma. Dig Dis Sci 54: 2109-2117, 2009.

73. Krämer $\mathrm{OH}$, Zhu P, Ostendorff $\mathrm{HP}$, Golebiewski M Tiefenbach J, Peters MA, Brill B, Groner B, Bach I, Heinzel T and Göttlicher M: The histone deacetylase inhibitor valproic acid selectively induces proteasomal degradation of HDAC2. EMBO J 22: 3411-3420, 2003

74. Brandl A, Wagner T, Uhlig KM, Knauer SK, Stauber RH, Melchior F, Schneider G, Heinzel T and Krämer OH: Dynamically regulated sumoylation of HDAC2 controls p53 deacetylation and restricts apoptosis following genotoxic stress. J Mol Cell Biol 4 284-293, 2012

75. Adenuga D and Rahman I: Protein kinase CK2-mediated phosphorylation of HDAC2 regulates co-repressor formation, deacetylase activity and acetylation of HDAC2 by cigarette smoke and aldehydes. Arch Biochem Biophys 498: 62-73, 2010.

76. Tsai SC and Seto E: Regulation of histone deacetylase 2 by protein kinase CK2. J Biol Chem 277: 31826-31833, 2002.

77. Chen PJ, Cai SP, Huang C, Meng XM and Li J: Protein tyrosine phosphatase 1B (PTP1B): A key regulator and therapeutic target in liver diseases. Toxicology 337: 10-20, 2015.

78. Kan C, Ungelenk L, Lupp A, Dirsch O and Dahmen U: Ischemia-Reperfusion injury in aged Livers-The energy metabolism, inflammatory response, and autophagy. Transplantation 102: 368-377, 2018.

79. Guicciardi ME, Malhi H, Mott JL and Gores GJ: Apoptosis and necrosis in the liver. Compr Physiol 3: 977-1010, 2013

80. Lei WW, Zhang KH, Pan XC, Wang DM, Hu Y, Yang YN and Song JG: Histone deacetylase 1 and 2 differentially regulate apoptosis by opposing effects on extracellular signal-regulated kinase 1/2. Cell Death Dis 1: e44, 2010.

81. Romero-Gallo J, Sozmen EG, Chytil A, Russell WE, Whitehead R, Parks WT, Holdren MS, Her MF, Gautam S, Magnuson M, et al: Inactivation of TGF-beta signaling in hepatocytes results in an increased proliferative response after partial hepatectomy. Oncogene 24: 3028-3041, 2005.

82. Raven A, Lu WY, Man TY, Ferreira-Gonzalez S, O'Duibhir E, Dwyer BJ, Thomson JP, Meehan RR, Bogorad R, Koteliansky V, et al: Cholangiocytes act as facultative liver stem cells during impaired hepatocyte regeneration. Nature 547: 350-354, 2017

83. Willis-Martinez D, Richards HW, Timchenko NA and Medrano EE: Role of HDAC1 in senescence, aging, and cancer. Exp Gerontol 45: 279-285, 2010.

84. Harms KL and Chen X: Histone deacetylase 2 modulates p53 transcriptional activities through regulation of p53-DNA binding activity. Cancer Res 67: 3145-3152, 2007.

85. Turgeon N, Blais M, Gagne JM, Tardif V, Boudreau F, Perreault N and Asselin C: HDAC1 and HDAC2 restrain the intestinal inflammatory response by regulating intestinal epithelial cell differentiation. PLoS One 8: e73785, 2013.

86. Ler SY, Leung CH, Khin LW, Lu GD, Salto-Tellez M, Hartman M, Iau PT, Yap CT and Hooi SC: HDAC1 and HDAC2 independently predict mortality in hepatocellular carcinoma by a competing risk regression model in a Southeast Asian population. Oncol Rep 34: 2238-2250, 2015.

87. Noh JH, Chang YG, Kim MG, Jung KH, Kim JK, Bae HJ, Eun JW, Shen Q, Kim SJ, Kwon SH, et al: MiR-145 functions as a tumor suppressor by directly targeting histone deacetylase 2 in liver cancer. Cancer Lett 335: 455-462, 2013.

88. Makar AB, Mcmartin KE, Palese M and Tephly TR: Formate assay in body fluids: Application in methanol poisoning App. Biochem Med 13: 117-126, 1975.

89. Noh JH, Jung KH, Kim JK, Eun JW, Bae HJ, Xie HJ, Chang YG, Kim MG, Park WS, Lee JY and Nam SW: Aberrant Regulation of HDAC2 Mediates proliferation of hepatocellular carcinoma cells by deregulating expression of G1/S cell cycle proteins. PLoS One 6: e28103, 2011 .
90. Yuan X, Yan S, Zhao J, Shi D, Yuan B, Dai W, Jiao B, Zhang W and Miao M: Lipid metabolism and peroxisome proliferator-activated receptor signaling pathways participate in late-phase liver regeneration. J Proteome Res 10: 1179-1190, 2011.

91. Michalopoulos GK and Bhushan B: Liver regeneration Biological and pathological mechanisms and implications. Nat Rev Gastroenterol Hepatol 18: 40-55, 2021

92. Michalopoulos GK: Principles of liver regeneration and growth homeostasis. Compr Physiol 3: 485-513, 2013.

93. Li L, Guo J, Chen Y, Chang C and Xu C: Comprehensive CircRNA expression profile and selection of key CircRNAs during priming phase of rat liver regeneration. BMC Genomics 18: 80, 2017.

94. Xia J, Zhou Y, Ji H, Wang Y, Wu Q, Bao J, Ye F, Shi Y and $\mathrm{Bu} \mathrm{H}$ : Loss of Histone Deacetylases 1 and 2 in hepatocytes impairs murine liver regeneration through Ki67 depletion. Hepatology 58: 2089-2098, 2013.

95. Wang Y, Ye F, Ke Q, Wu Q, Yang R and Bu H: Gender-dependent histone deacetylases injury may contribute to differences in liver recovery rates of male and female mice. Transplant Proc 45: 463-473, 2013

96. Bansal R, Nagorniewicz B and Prakash J: Clinical advancements in the targeted therapies against liver fibrosis. Mediators Inflamm 2016: 7629724, 2016

97. Aydın MM and Akçalı KC: Liver fibrosis. Turk J Gastroenterol 29: 14-21, 2018

98. Gounder PP, Haering C, Bruden DJ, Townshend-Bulson L, Simons BC, Spradling PR and McMahon BJ: Does incorporating change in APRI or FIB-4 indices over time improve the accuracy of a single index for identifying liver fibrosis in persons with chronic hepatitis $\mathrm{C}$ virus infection? J Clin Gastroenterol 52: 60-66, 2018.

99. Bilal U, Lau B, Lazo M, McCaul ME, Hutton HE, Sulkowski MS, Moore RD and Chander G: Interaction between alcohol consumption patterns, antiretroviral therapy type, and liver fibrosis in persons living with HIV. AIDS Patient Care STDS 30: 200-207, 2016

100. Lainé F, Bendavid C, Moirand R, Tessier S, Perrin M, Guillygomarc'h A, Guyader D, Calon E, Renault A, Brissot $\mathrm{P}$, et al: Prediction of liver fibrosis in patients with features of the metabolic syndrome regardless of alcohol consumption. Hepatology 39: 1639-1646, 2004.

101. Sunami Y, Leithäuser F, Gul S, Fiedler K, Güldiken N, Espenlaub S, Holzmann KH, Hipp N, Sindrilaru A, Luedde T, et al: Hepatic activation of IKK/NFKB signaling induces liver fibrosis via macrophage-mediated chronic inflammation. Hepatology 56: 1117-1128, 2012

102. Zhang H, Wu P, Chen F, Hao Y, Lao Y, Ren L, Sun L, Sun W, Wei H, Chan DW, et al: SILAC-based quantitative proteomic analysis of secretome between activated and reverted hepatic stellate cells. Proteomics 14: 1977-1986, 2014

103. Mannaerts I, Eysackers N, Onyema OO, Van Beneden K, Valente S, Mai A, Odenthal M and van Grunsven LA: Class II HDAC inhibition hampers hepatic stellate cell activation by induction of microRNA-29. PLoS One 8: e55786, 2013.

104. Pannem RR, Dorn C, Hellerbrand C and Massoumi R Cylindromatosis gene CYLD regulates hepatocyte growth factor expression in hepatic stellate cells through interaction with histone deacetylase 7. Hepatology 60: 1066-1081, 2014

105. Mannaerts I, Nuytten NR, Rogiers V, Vanderkerken K, van Grunsven LA and Geerts A: Chronic administration of valproic acid inhibits activation of mouse hepatic stellate cells in vitro and in vivo. Hepatology 51: 603-614, 2010.

106. Qin L and Han YP: Epigenetic repression of matrix metalloproteinases in myofibroblastic hepatic stellate cells through histone deacetylases 4: Implication in tissue fibrosis. Am J Pathol 177: 1915-1928, 2010.

107. Huang SK, Scruggs AM, Donaghy J, Horowitz JC, Zaslona Z, Przybranowski S, White ES and Peters-Golden M: Histone modifications are responsible for decreased Fas expression and apoptosis resistance in fibrotic lung fibroblasts. Cell Death Dis 4: e621, 2013.

108. Lee YH, Seo D, Choi KJ, Andersen JB, Won MA, Kitade M, Gómez-Quiroz LE, Judge AD, Marquardt JU, Raggi C, et al: Antitumor effects in hepatocarcinoma of isoform-selective inhibition of HDAC2. Cancer Res 74: 4752-4761, 2014

109. Li X, Wu XQ, Xu T, Li XF, Yang Y, Li WX, Huang C, Meng XM and Li J: Role of histone deacetylases(HDACs) in progression and reversal of liver fibrosis. Toxicol Appl Pharmacol 306: $58-68,2016$ 
110. Dooley S, Hamzavi J, Breitkopf K, Wiercinska E, Said HM, Lorenzen J, Ten Dijke P and Gressner AM: Smad7 prevents activation of hepatic stellate cells and liver fibrosis in rats. Gastroenterology 125: 178-191, 2003

111. Dooley S, Hamzavi J, Ciuclan L, Godoy P, Ilkavets I, Ehnert S, Ueberham E, Gebhardt R, Kanzler S, Geier A, et al: Hepatocyte-specific Smad7 expression attenuates TGF-betamediated fibrogenesis and protects against liver damage. Gastroenterology 135: 642-659, 2008.

112. Hamzavi J, Ehnert S, Godoy P, Ciuclan L, Weng H, Mertens PR, Heuchel R and Dooley S: Disruption of the Smad7 gene enhances CCI4-dependent liver damage and fibrogenesis in mice. J Cell Mol Med 12 (5B): 2130-2144, 2008.

113. Oseini AM and Sanyal AJ: Therapies in non-alcoholic steatohepatitis (NASH). Liver Int 37 (Suppl 1): S97-S103, 2017.

114. Utsunomiya H, Yamamoto Y, Takeshita E, Tokumoto Y, Tada F Miyake T, Hirooka M, Abe M, Kumagi T, Matsuura B, et al Upregulated absorption of dietary palmitic acids with changes in intestinal transporters in non-alcoholic steatohepatitis (NASH). J Gastroenterol 52: 940-954, 2017.

115. Fukushima J, Kamada Y, Matsumoto H, Yoshida Y, Ezaki H, Takemura T, Saji Y, Igura T, Tsutsui S, Kihara S, et al: Adiponectin prevents progression of steatohepatitis in mice by regulating oxidative stress and Kupffer cell phenotype polarization. Hepatol Res 39: 724-738, 2009.

116. Afrin R,Arumugam S, Rahman A, Wahed MI,KaruppagounderV, Harima M, Suzuki H, Miyashita S, Suzuki K, Yoneyama H, et al: Curcumin ameliorates liver damage and progression of NASH in NASH-HCC mouse model possibly by modulating HMGB1-NF- $\kappa$ B translocation. Int Immunopharmacol 44: 174-182, 2017.

117. Zhong S, Zhao L, Wang Y, Zhang C, Liu J, Wang P, Zhou W, Yang P, Varghese Z, Moorhead JF, et al: CD36 deficiency aggravates macrophage infiltration and hepatic inflammation by up-regulating MCP-1 expression of hepatocytes through HDAC2-dependant pathway. Antioxid Redox Signal: Aug 1, 2017 (Epub ahead of print). doi: 10.1089/ars.2016.6808).

118. Torre LA, Bray F, Siegel RL, Ferlay J, Lortet-Tieulent J and Jemal A: Global cancer statistics, 2012. CA Cancer J Clin 65 87-108, 2015.

119. Chen Z, Xie H, Hu M, Huang T, Hu Y, Sang N and Zhao Y Recent progress in treatment of hepatocellular carcinoma. Am J Cancer Res 10: 2993-3036, 2020.

120. Lee JS, Chu IS, Heo J, Calvisi DF, Sun Z, Roskams T, Durnez A, Demetris AJ and Thorgeirsson SS: Classification and prediction of survival in hepatocellular carcinoma by gene expression profiling. Hepatology 40: 667-676, 2004

121. Ropero S and Esteller M: The role of histone deacetylases (HDACs) in human cancer. Mol Oncol 1: 19-25, 2007.

122. Bayat S, Mansoori Derakhshan S, Mansoori Derakhshan N Shekari Khaniani M and Alivand MR: Downregulation of HDAC2 and HDAC3 via oleuropein as a potent prevention and therapeutic agent in MCF-7 breast cancer cells. J Cell Biochem 120: 9172-9180, 2019.

123. Quint K, Agaimy A, Di Fazio P, Montalbano R, Steindorf C, Jung R, Hellerbrand C, Hartmann A, Sitter H, Neureiter D and Ocker M: Clinical significance of histone deacetylases 1, 2, 3, and 7: HDAC2 is an independent predictor of survival in HCC. Virchows Arch 459: 129-139, 2011.

124. Kim HS, Chang YG, Bae HJ, Eun JW, Shen Q, Park SJ, Shin WC, Lee EK, Park S, Ahn YM, et al: Oncogenic potential of CK20 and its regulatory role in EGF-induced HDAC2 expression in human liver cancer. FEBS J 281: 851-861, 2014.

125. Noh JH, Bae HJ, Eun JW, Shen Q, Park SJ, Kim HS, Nam B Shin WC, Lee EK, Lee K, et al: HDAC2 provides a critica support to malignant progression of hepatocellular carcinoma through feedback control of mTORC1 and AKT. Cancer Res 74 1728-1738, 2014.

126. Huang J, Yang G, Huang Y, Kong W and Zhang S: 1,25(OH)2D3 inhibits the progression of hepatocellular carcinoma via downregulating HDAC2 and upregulating P21(WAFI/CIP1). Mol Med Rep 13: 1373-1380, 2016.

127. Huang J, Yang G, Huang Y and Zhang S: Inhibitory effects of $1,25(\mathrm{OH}) 2 \mathrm{D} 3$ on the proliferation of hepatocellular carcinoma cells through the downregulation of HDAC2. Oncol Rep 38 $1845-1850,2017$.

128. Wang H, Kohashi K, Yoshizumi T, Okumura Y, Tanaka Y, Shimokawa M, Iwasaki T, Aishima S, Maehara Y and Oda Y: Coexpression of SALL4 with HDAC1 and/or HDAC2 is associated with underexpression of PTEN and poor prognosis in patients with hepatocellular carcinoma. Hum Pathol 64: 69-75, 2017.
129. Gryder BE, Pomella S, Sayers C, Wu XS, Song Y, Chiarella AM, Bagchi S, Chou HC, Sinniah RS, Walton A, et al: Histone hyperacetylation disrupts core gene regulatory architecture in rhabdomyosarcoma. Nat Genet 51: 1714-1722, 2019.

130. Methot JL, Hamblett CL, Mampreian DM, Jung J, Harsch A, Szewczak AA, Dahlberg WK, Middleton RE, Hughes B, Fleming JC, et al: SAR profiles of spirocyclic nicotinamide derived selective HDAC1/HDAC2 inhibitors (SHI-1:2). Bioorg Med Chem Lett 18: 6104-6109, 2008.

131. Methot JL, Chakravarty PK, Chenard M, Close J, Cruz JC, Dahlberg WK, Fleming J, Hamblett CL, Hamill JE, Harrington P, et al: Exploration of the internal cavity of histone deacetylase (HDAC) with selective HDAC1/HDAC2 inhibitors (SHI-1:2). Bioorg Med Chem Lett 18: 973-978, 2008.

132. Qi Z, Wang C, Jiang J and Wu C: Novel C15 Triene Triazole, D-A derivatives anti-HepG2, and as HDAC2 inhibitors: A synergy study. Int J Mol Sci 19: 3184, 2018.

133. Venturelli S, Niessner H, Sinnberg T, Berger A, Burkard M, Urmann C, Donaubauer K, Böcker A, Leischner C, Riepl H, et al: 6- and 8-Prenylnaringenin, novel natural histone deacetylase inhibitors found in hops, exert antitumor activity on melanoma cells. Cell Physiol Biochem 51: 543-556, 2018.

134. Al-Sanea MM, Gotina L, Mohamed MF, Grace Thomas Parambi D, Gomaa HA, Mathew B, Youssif BG, Alharbi KS Elsayed ZM, Abdelgawad MA and Eldehna WM: Design, synthesis and biological evaluation of new HDAC1 and HDAC2 inhibitors endowed with ligustrazine as a novel cap moiety. Drug Des Devel Ther 14: 497-508, 2020.

135. Jang YG, Hwang KA and Choi KC: Rosmarinic acid, a component of rosemary tea, induced the cell cycle arrest and apoptosis through modulation of HDAC2 expression in prostate cancer cell lines. Nutrients 10: 1784, 2018.

136. Deng L, Tang J, Yang H, Cheng C, Lu S, Jiang R and Sun B: MTA1 modulated by miR-30e contributes to epithelial-to-mesenchymal transition in hepatocellular carcinoma through an ErbB2-dependent pathway. Oncogene 36: 3976-3985, 2017.

137. Buurman R, Gürlevik E, Schäffer V, Eilers M, Sandbothe M, Kreipe H, Wilkens L, Schlegelberger B, Kühnel F and Skawran B: Histone deacetylases activate hepatocyte growth factor signaling by repressing MicroRNA-449 in hepatocellular carcinoma cells. Gastroenterology 143: 811-820.e15, 2012.

138. He QL, Qin SY, Tao L, Ning HJ and Jiang HX: Prognostic value and prospective molecular mechanism of miR-100-5p in hepatocellular carcinoma: A comprehensive study based on 1,258 samples. Oncol Lett 18: 6126-6142, 2019.

139. Kim HS, Lee KS, Bae HJ, Eun JW, Shen Q, Park SJ, Shin WC, Yang HD, Park M, Park WS, et al: MicroRNA-31 functions as a tumor suppressor by regulating cell cycle and epithelial-mesenchymal transition regulatory proteins in liver cancer. Oncotarget 6: 8089-8102, 2015.

140. Dai W, Dai JL, Tang MH, Ye MS and Fang S: IncRNA-SNHG15 accelerates the development of hepatocellular carcinoma by targeting $\mathrm{miR}-490-3$ p/histone deacetylase 2 axis. World J Gastroenterol 25: 5789-5799, 2019.

141. Turner BM: Cellular memory and the histone code. Cell 111: 285-291, 2002

142. Khan SN and Khan AU: Role of histone acetylation in cell physiology and diseases: An update. Clin Chim Acta 411: 1401-1411, 2010

143. Budillon A, Di Gennaro E, Bruzzese F, Rocco M, Manzo G and Caraglia M: Histone deacetylase inhibitors: A new wave of molecular targeted anticancer agents. Recent Pat Anticancer Drug Discov 2: 119-134, 2007

144. Wade PA: Transcriptional control at regulatory checkpoints by histone deacetylases: Molecular connections between cancer and chromatin. Hum Mol Genet 10: 693-698, 2001.

145. Forsberg EC and Bresnick EH: Histone acetylation beyond promoters: Long-range acetylation patterns in the chromatin world. Bioessays 23: 820-830, 2001

146. Zhang L, Qiu Z, Hu Y, Yang F, Yan S, Zhao L, Li B, He S, Huang M, Li J and Li L: ABA treatment of germinating maize seeds induces VP1 gene expression and selective promoter-associated histone acetylation. Physiol Plant 143: 287-296, 2011.

147. Tian XL, Lu X, Feng JB, Cai TJ, Li S, Tian M and Liu QJ: Alterations in histone acetylation following exposure to ${ }^{60} \mathrm{Co}$ $\mathrm{Y}$-rays and their relationship with chromosome damage in human lymphoblastoid cells. Radiat Environ Biophys 57: 215-222, 2018 
148. Heinz KS, Rapp A, Casas-Delucchi CS, Lehmkuhl A Romero-Fernández I, Sánchez A, Krämer OH, Marchal JA and Cardoso MC: DNA replication dynamics of vole genome and its epigenetic regulation. Epigenetics Chromatin 12: 18, 2019.

149. Ibi D, de la Fuente Revenga M, Kezunovic N, Muguruza C, Saunders JM, Gaitonde SA, Moreno JL, Ijaz MK, Santosh V, Kozlenkov A, et al: Antipsychotic-induced Hdac2 transcription via NF-kB leads to synaptic and cognitive side effects. Nat Neurosci 20: 1247-1259, 2017.

150. Bhandari DR, Seo KW, Jung JW, Kim HS, Yang SR and Kang KS: The regulatory role of c-MYC on HDAC2 and PcG expression in human multipotent stem cells. J Cell Mol Med 15: 1603-1614, 2011.
151. Yang H, Salz T, Zajac-Kaye M, Liao D, Huang S and Qiu Y: Overexpression of histone deacetylases in cancer cells is controlled by interplay of transcription factors and epigenetic modulators. FASEB J 28: 4265-4279, 2014.

This work is licensed under a Creative Commons Attribution-NonCommercial-NoDerivatives 4.0 International (CC BY-NC-ND 4.0) License. 